\title{
Phenobarbital, Midazolam Pharmacokinetics, Effectiveness, and Drug-Drug Interaction in Asphyxiated Neonates Undergoing Therapeutic Hypothermia
}

\author{
Laurent M.A. Faviéa, ${ }^{a} \quad$ Floris Groenendaal ${ }^{b, c}$ Marcel P.H. van den Broek ${ }^{d}$ \\ Carin M.A. Rademaker ${ }^{a}$ Timo R. de Haan ${ }^{2}$ Henrica L.M. van Straaten ${ }^{f}$ \\ Peter H. Dijk ${ }^{g}$ Arno van Heijst ${ }^{\text {h }}$ Sinno H.P. Simons ${ }^{i}$ \\ Koen P. Dijkman ${ }^{j}$ Monique Rijken ${ }^{k}$ Inge A. Zonnenberg' \\ Filip Cools ${ }^{m}$ Alexandra Zecic ${ }^{n}$ Johanna H. van der Lee ${ }^{\circ}$ \\ Debbie H.G.M. Nuytemans ${ }^{p}$ Frank van Bel ${ }^{b, c}$ Toine C.G. Egberts ${ }^{a, q}$ \\ Alwin D.R. Huitema ${ }^{a}{ }^{r}$ on behalf of the PharmaCool study group
}

\begin{abstract}
a Department of Clinical Pharmacy, University Medical Center Utrecht, Utrecht University, Utrecht, The Netherlands;
${ }^{b}$ Department of Neonatology, Wilhelmina Children's Hospital, University Medical Center Utrecht and Utrecht

University, Utrecht, The Netherlands; ' ${ }^{\mathrm{C} B r a i n}$ Center Rudolf Magnus, University Medical Center Utrecht, Utrecht, The Netherlands; ${ }^{d}$ Department of Clinical Pharmacy, St. Antonius Hospital, Nieuwegein, The Netherlands; ${ }^{e}$ Department of Neonatology, Emma Children's Hospital, Academic Medical Center, Amsterdam University Medical Center, Amsterdam, The Netherlands; ${ }^{f}$ Department of Neonatology, Isala Clinics, Zwolle, The Netherlands; ${ }^{9}$ Department of Neonatology, Groningen University Medical Centre, Groningen, The Netherlands; ${ }^{\mathrm{h}}$ Department of Neonatology, Radboud University Medical Center-Amalia Children's Hospital, Nijmegen, The Netherlands; 'Division of Neonatology, Department of Pediatrics, Erasmus Medical Centre-Sophia Children's Hospital, Rotterdam, The Netherlands; ${ }^{j}$ Department of

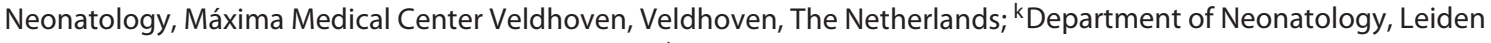
University Medical Center, Leiden, The Netherlands; 'Department of Neonatology, VU University Medical Center,

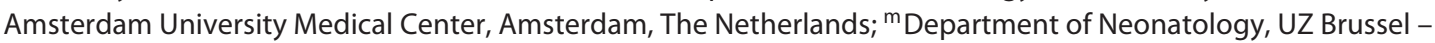
Vrije Universiteit Brussel, Brussels, Belgium; ' Department of Neonatology, University Hospital Gent, Gent, Belgium; -Paediatric Clinical Research Office, Emma Children's Hospital, Academic Medical Center, Amsterdam University

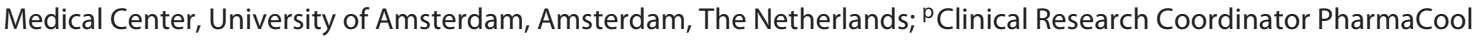

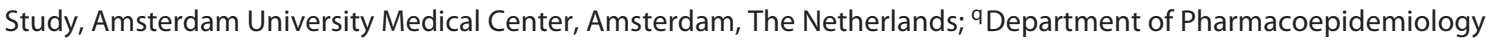

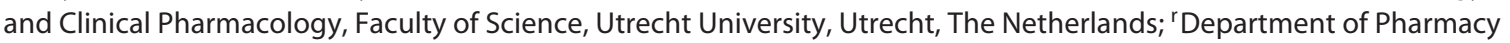
and Pharmacology, Netherlands Cancer Institute, Amsterdam, The Netherlands
\end{abstract}

\section{Keywords}

Phenobarbital · Midazolam · Pharmacokinetics ·

Hypoxic-ischaemic encephalopathy · Neonates

A complete list of non-author contributors appears in the Acknowledgements section.

\section{KARGER}

E-Mail karger@karger.com www.karger.com/neo
(C) 2019 The Author(s) Published by S. Karger AG, Basel

Karger

Open access

This article is licensed under the Creative Commons AttributionNonCommercial-NoDerivatives 4.0 International License (CC BY NC-ND) (http://www.karger.com/Services/OpenAccessLicense). Usage and distribution for commercial purposes as well as any distribution of modified material requires written permission.

\begin{abstract}
Background: Phenobarbital and midazolam are commonly used drugs in (near-)term neonates treated with therapeutic hypothermia for hypoxic-ischaemic encephalopathy, for sedation, and/or as anti-epileptic drug. Phenobarbital is an inducer of cytochrome P450 (CYP) 3A, while midazolam is a
\end{abstract}

Laurent M.A. Favié

Department of Clinical Pharmacy, University Medical Center Utrecht Heidelberglaan 100

NL-3584 CX, Utrecht (The Netherlands)

E-Mail lfavie2@umcutrecht.nl 
CYP3A substrate. Therefore, co-treatment with phenobarbital might impact midazolam clearance. Objectives: To assess pharmacokinetics and clinical anti-epileptic effectiveness of phenobarbital and midazolam in asphyxiated neonates and to develop dosing guidelines. Methods: Data were collected in the prospective multicentre PharmaCool study. In the present study, neonates treated with therapeutic hypothermia and receiving midazolam and/or phenobarbital were included. Plasma concentrations of phenobarbital and midazolam including its metabolites were determined in blood samples drawn on days 2-5 after birth. Pharmacokinetic analyses were performed using non-linear mixed effects modelling; clinical effectiveness was defined as no use of additional anti-epileptic drugs. Results: Data were available from 113 (phenobarbital) and 118 (midazolam) neonates; 68 were treated with both medications. Only clearance of 1-hydroxy midazolam was influenced by hypothermia. Phenobarbital co-administration increased midazolam clearance by a factor $2.3(95 \% \mathrm{Cl} 1.9-2.9, p<0.05)$. Anticonvulsant effectiveness was $65.5 \%$ for phenobarbital and $37.1 \%$ for addon midazolam. Conclusions: Therapeutic hypothermia does not influence clearance of phenobarbital or midazolam in (near-)term neonates with hypoxic-ischaemic encephalopathy. A phenobarbital dose of $30 \mathrm{mg} / \mathrm{kg}$ is advised to reach therapeutic concentrations. Phenobarbital co-administration significantly increased midazolam clearance. Should phenobarbital be substituted by non-CYP3A inducers as first-line anticonvulsant, a 50\% lower midazolam maintenance dose might be appropriate to avoid excessive exposure during the first days after birth.

(c) 2019 The Author(s)

Published by S. Karger AG, Basel

\section{Introduction}

Hypoxic-ischaemic encephalopathy (HIE) caused by perinatal asphyxia is a serious clinical condition with significant morbidity and mortality in (near-)term neonates. Globally, the incidence varies between 0.5 and 20 of every 1,000 live born neonates [1]. Therapeutic hypothermia (TH) is an established neuroprotective treatment which has markedly reduced the composite adverse outcome of death and neurodevelopmental disorders. In the Netherlands, 150-200 neonates are eligible for this treatment annually $[2,3]$.

Phenobarbital and midazolam are commonly prescribed drugs in this vulnerable population. Phenobarbital is a first-line anti-epileptic drug (AED). It acts through stimulation of the $\gamma$-aminobutyric acid (GABA) receptors in the central nervous system, which leads to a postsynap-

Phenobarbital and Midazolam Pharmacokinetics in Neonates tic increase in chloride ions, thereby reducing neuronal excitability [4]. Phenobarbital has a half-life of approximately a week in neonates. Therefore, it can be administered as single or rapidly consecutive bolus administrations up to $40 \mathrm{mg} / \mathrm{kg}$. Plasma concentrations between 20 and $40 \mathrm{mg} / \mathrm{L}$ are considered effective and safe [5]. Midazolam is a benzodiazepine which also interacts with the GABA receptor. It is used as a second-line AED when phenobarbital is ineffective [6]. Additionally, it is used for sedation for instance in neonates who require mechanical ventilation [7]. Midazolam has a relatively short half-life of several hours in neonates and is usually administrated via continuous infusion. For sedation, doses around 0.1 $\mathrm{mg} / \mathrm{kg} / \mathrm{h}$ are often sufficient, while as an AED, doses up to or even exceeding $0.3 \mathrm{mg} / \mathrm{kg} / \mathrm{h}$ have been used. The therapeutic window for midazolam is not well defined but plasma concentrations of at least $0.1 \mathrm{mg} / \mathrm{L}$ are required for both indications. Higher plasma concentrations are associated with increased AED effectiveness [8]. Levels above $2.4 \mathrm{mg} / \mathrm{L}$ are considered toxic [9].

Midazolam undergoes hepatic metabolism by cytochrome P450 (CYP) 3A into 1-hydroxymidazolam $(\mathrm{OHM})$. OHM is further metabolised into hydroxymidazolam glucuronide (HMG) which is excreted renally. Both metabolites are pharmacologically active, and accumulation has been associated with prolonged sedation $[10,11]$. Phenobarbital is known as a potent inducer of several CYP enzymes in adults, including CYP3A [12].

Pharmacokinetics (PK) of drugs in neonates differs from older children and adults due to immaturity of the involved organs. CYP expression is impaired at birth but is subject to (rapid) maturation in the first few days of life $[13,14]$. Midazolam clearance could potentially be increased if phenobarbital is also administered, but it is uncertain whether this drug-drug interaction is present in neonates. Induction of midazolam clearance might have important consequences for the use of this drug in this population since adequate control of neonatal seizures is important to reduce the risk of neurological disabilities [15-17].

Hypothermia could influence various physiological processes relevant for $\mathrm{PK}$ such as organ perfusion, protein binding, and (metabolic) enzymatic activity [18-20]. Previous studies from our group have assessed the effect of TH on PK of both phenobarbital and midazolam in this population using data from two tertiary neonatal intensive care units (NICU) as well as clinical effectiveness as $\operatorname{AED}[5,8]$. Clearance of neither drug was found to be affected by TH. Sufficient seizure control was achieved in $66 \%$ of all neonates with phenobarbital monotherapy. 
Table 1. Patient characteristics

\begin{tabular}{|c|c|c|c|}
\hline \multirow[t]{2}{*}{ Parameter } & \multirow[t]{2}{*}{ Phenobarbital $(n=113)$} & \multicolumn{2}{|l|}{ Midazolam $(n=118)$} \\
\hline & & PB yes $(n=68)$ & PB no $(n=50)$ \\
\hline Gestational age, weeks & $39.8 \pm 1.7$ & $40.2 \pm 1.4$ & $39.8 \pm 1.6$ \\
\hline Birth weight, g & $3,382 \pm 582$ & $3,450 \pm 540$ & $3,495 \pm 674$ \\
\hline Male & $63(55.8)$ & $35(51.5)$ & $36(72)$ \\
\hline $\mathrm{pH}^{\mathrm{a}}$ & $7.02(6.85$ to 7.15$)$ & $6.98(6.80$ to 7.10$)$ & $6.90(6.80$ to 7.05$)$ \\
\hline Lactate $^{\mathrm{a}}, \mathrm{mmol} / \mathrm{L}$ & $13.0(9.0$ to 18.2$)$ & $14.1(11.4$ to 16.6$)$ & $12.0(7.8-14.6)$ \\
\hline Base excess $^{\mathrm{a}}, \mathrm{mmol} / \mathrm{L}$ & $-18.0(-12.0$ to -22.0$)$ & $-18.0(-22.0$ to -12.0$)$ & $-18.5(-21$ to -14.3$)$ \\
\hline Thompson score ${ }^{b}$ & $9(8-13)$ & $10(8$ to 14$)$ & $9(7-10)$ \\
\hline Midazolam sedation only & - & $33(48.3)$ & $50(100)$ \\
\hline Midazolam AED & - & $35(51.5)$ & $0(0)$ \\
\hline \multicolumn{4}{|l|}{ aEEG on admission ${ }^{\mathrm{b}}$} \\
\hline Continuous normal voltage & $16(14.2)$ & $8(11.8)$ & $10(20.0)$ \\
\hline Discontinuous normal voltage & $45(39.8)$ & $20(29.4)$ & $29(58.0)$ \\
\hline Of whom $<5 \mu \mathrm{V}$ & $16(14.2)$ & $9(13.2)$ & $14(28.0)$ \\
\hline Burst suppression & $26(23.0)$ & $21(30.9)$ & $6(12.0)$ \\
\hline Continuous low voltage & $5(4.4)$ & $4(5.9)$ & $1(2.0)$ \\
\hline Flat trace & $17(15.0)$ & $13(19.1)$ & $1(2.0)$ \\
\hline Unknown & $4(3.5)$ & $2(2.9)$ & $3(6.0)$ \\
\hline Mortality & $32(28.3)$ & $27(39.7)$ & $1(2.0)$ \\
\hline
\end{tabular}

Data are presented as mean \pm standard deviation, median (interquartile range), or $n(\%)$. PB, phenobarbital co-medication; AED, anti-epilpetic drug; aEEG, amplitude-integrated electroencephalogram. ${ }^{\text {a }}$ Value measured in umbilical cord blood or, if unavailable, from arterial or venous blood within $1 \mathrm{~h}$ after birth. ${ }^{\mathrm{b}}$ Encephalopathy was characterized by a Thompson score of $>71 \mathrm{~h}$ after birth or an abnormal aEEG (i.e., background pattern DNV $<5 \mu \mathrm{V}$ or worse or seizures) on admission to a level III NICU.

When midazolam was started as a second-line AED, effectiveness was $23 \%$.

The objective of the present study was to expand the current PK knowledge of phenobarbital and midazolam in neonates undergoing TH as treatment for HIE, to evaluate the previously developed models with an external dataset, to assess the effectiveness of each AED, and to develop PK-based dosing guidelines. In post hoc analyses, the influence of phenobarbital co-administration on midazolam clearance was investigated.

\section{Methods}

\section{Setting and Study Population}

The multi-centre prospective study PharmaCool was designed to investigate the $\mathrm{PK}$ of frequently used drugs during $\mathrm{TH}$ and rewarming in neonates suffering from HIE. Inclusion and exclusion criteria have been described previously [21]. Parental informed consent was obtained in all cases. The choice of therapy and drug dosing was not influenced by the study protocol. The PharmaCool study was approved by the Ethics Committees of all twelve participating NICUs in the Netherlands and Belgium.

\section{Dosing and Administration}

Phenobarbital was dosed as a single or repeated bolus short infusion of 10 of $20 \mathrm{mg} / \mathrm{kg}$, up to a cumulative dose of $40 \mathrm{mg} / \mathrm{kg}$. Midazolam was administrated as continuous infusion, both for sedation and as AED, with a starting dose of $0.05 \mathrm{mg} / \mathrm{kg} / \mathrm{h}$ for sedation and $0.1 \mathrm{mg} / \mathrm{kg} / \mathrm{h}$ for seizure control and titrated to effect. Both regimens can be preceded by a loading dose of $0.05-0.1 \mathrm{mg} / \mathrm{kg}$.

\section{Sampling and Bioanalysis}

Blood samples were drawn once daily on days $2-5$ after birth both during hypothermia and rewarming/normothermia [21]. Plasma concentrations of phenobarbital, midazolam, OHM, and HMG were determined using liquid chromatography-tandem mass spectrometry (LC-MS/MS). Details are available in the online Appendix (see www.karger.com/doi/10.1159/000/499330 for all online suppl. material).

\section{Population Pharmacokinetic Analyses}

PK analyses were performed using non-linear mixed effects modelling NONMEM (version 7.3, Icon Development Solutions) [22]. Birth weight was used as a descriptor for body size and was related to pharmacokinetic parameters using allometric relationships. Based on previous publications from our group, a one-compartment model for phenobarbital and a one-compartment model for midazolam with consecutive one-compartment models for both metabolites were used as structural models [5, 8]. Gestation- 


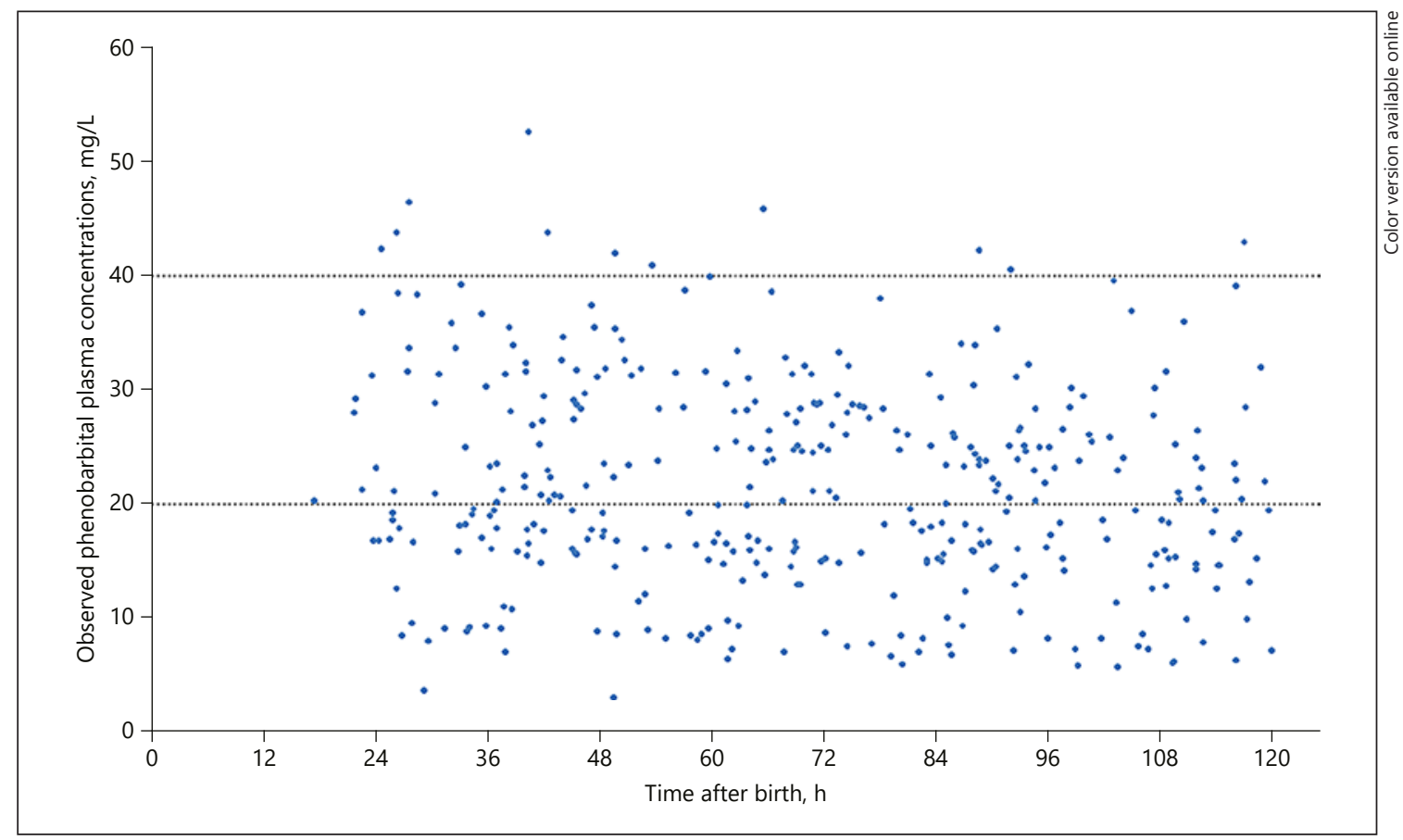

Fig. 1. Observed phenobarbital plasma concentrations versus time after birth. Dotted lines indicate the proposed therapeutic window of $20-40 \mathrm{mg} / \mathrm{L}$.

al age (GA), postnatal age (PNA), and body temperature (TEMP) were tested as covariates on clearance in both models. Phenobarbital co-medication was tested as covariate on clearance in the midazolam model. Parameter precision was assessed with sampling importance resampling [23].

Anticonvulsant Effectiveness

Treatment with phenobarbital was considered effective if no additional AED was started. In patients receiving midazolam for seizure control, effectiveness as second-line AED was defined as no requirement for a third-line AED.

\section{Dosing Guideline Development}

Several dosing regimens based on the current clinical practice were simulated using the parameter estimates of the final pharmacokinetic models. Phenobarbital single doses of 20, 30, and $40 \mathrm{mg} /$ $\mathrm{kg}$ were evaluated. Midazolam was tested with a loading dose of 0.05 or $0.1 \mathrm{mg} / \mathrm{kg}$ followed by continuous infusions varying between 0.05 and $0.3 \mathrm{mg} / \mathrm{kg} / \mathrm{h}$.

\section{Results}

\section{Patient Characteristics}

Phenobarbital data were available for 113 patients. $\mathrm{Cu}-$ mulative doses varied between 4.9 and $62.6 \mathrm{mg} / \mathrm{kg}$. Midazolam data were available from 118 patients (sedative $n=83$, AED $n=35)$. Of these, $68(57.6 \%)$ were also treat- ed with phenobarbital. Midazolam maintenance dose for sedation rarely exceeded $0.15 \mathrm{mg} / \mathrm{kg} / \mathrm{h}$. Highest midazolam maintenance dose as AED was $0.45 \mathrm{mg} / \mathrm{kg} / \mathrm{h}$. Patient characteristics are presented in Table 1.

Phenobarbital plasma concentrations were measured in 378 samples of which 219 (57.9\%) were taken during TH. Plasma concentrations varied between 9.1 and 52.6 $\mathrm{mg} / \mathrm{L}$ (Fig. 1). Plasma concentrations of midazolam, OHM and HMG were measured in 376 samples, of which 214 (56.9\%) were taken during TH. Plasma concentrations for midazolam varied between 0.02 and 3.25 $\mathrm{mg} / \mathrm{L}$ (Fig. 2), for OHM between 0.02 and $1.05 \mathrm{mg} / \mathrm{L}$, and for HMG between 0.02 and $8.34 \mathrm{mg} / \mathrm{L}$ (online Appendix).

\section{Population Pharmacokinetic Analyses}

Phenobarbital PK was best described by a one-compartment model. No influence of GA, PNA or TEMP could be detected on clearance. Midazolam PK was described by a one-compartment model with subsequent one-compartment models for OHM and HMG. GA and PNA did not affect clearance of any compound; TEMP significantly influenced only OHM clearance; clearance during $\mathrm{TH}$ was reduced by $25.7 \%\left(p<0.05,8.6 \% /{ }^{\circ} \mathrm{C}\right.$, $95 \%$ CI $\left.5.6-11.5 \% /{ }^{\circ} \mathrm{C}\right)$. Phenobarbital co-medication 


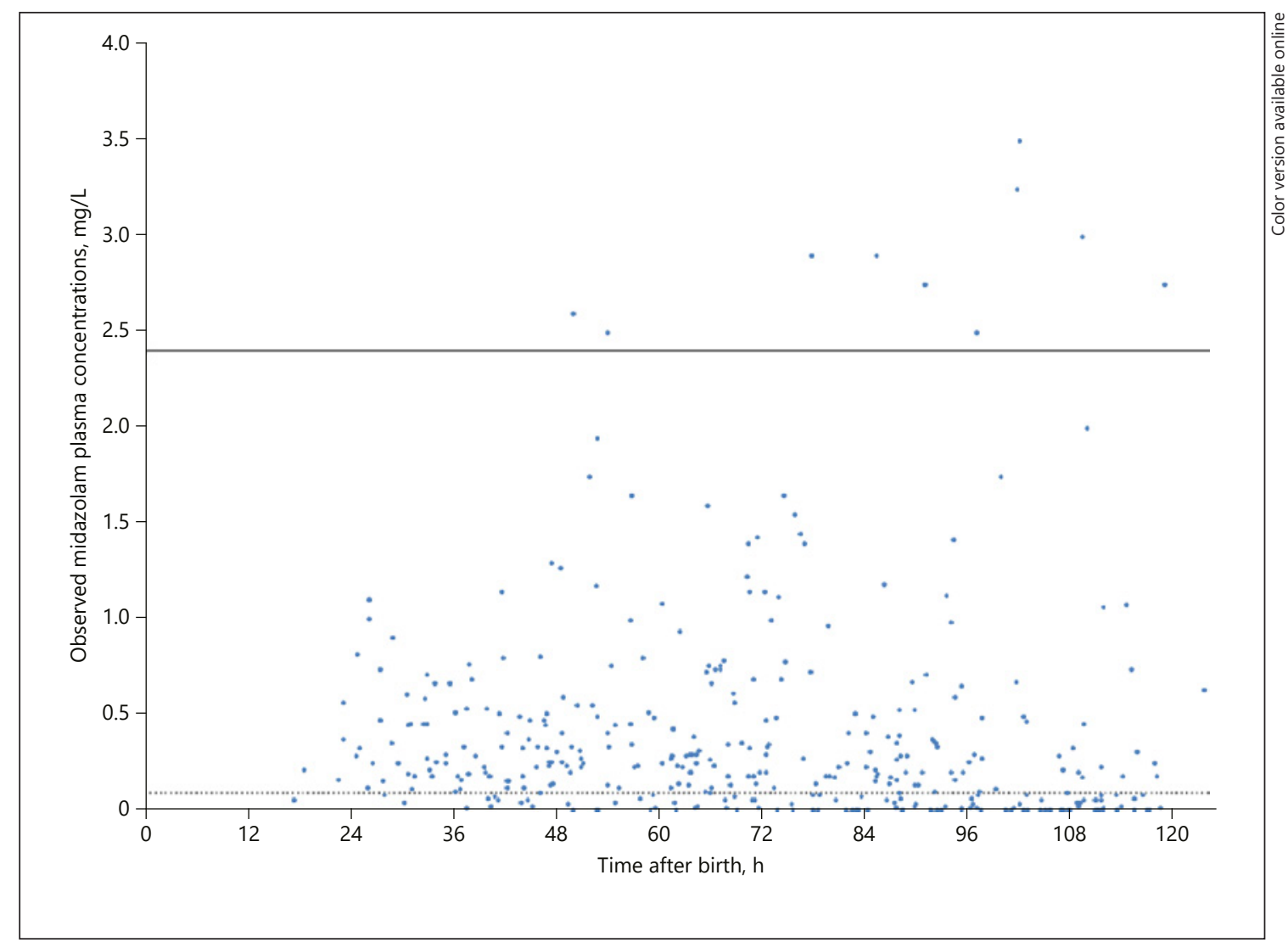

Fig. 2. Observed midazolam plasma concentrations versus time after birth. Dotted line indicates the minimal effective plasma concentration of $0.1 \mathrm{mg} / \mathrm{L}$. Solid line represents toxic upper limit of $2.4 \mathrm{mg} / \mathrm{L}$.

significantly influenced midazolam clearance. In absence of phenobarbital, midazolam clearance for a neonate of $3.5 \mathrm{~kg}$ was $0.35 \mathrm{~L} / \mathrm{h}(95 \%$ CI $0.29-0.41 \mathrm{~L} / \mathrm{h})$. In patients with phenobarbital co-medication, midazolam clearance was 2.3 -fold higher ( $p<0.05,95 \%$ CI 1.9-2.9). This effect was consistent over the entire study period and independent of phenobarbital dose, $\mathrm{TH}$, or indication for midazolam use. Pharmacokinetic parameter estimates of the final models are shown in Table 2. Further details of the population PK analyses are available in the online Appendix.

\section{Anticonvulsant Effectiveness}

Seizure control with phenobarbital monotherapy was achieved in 74 patients (65.5\%). Thirty-five patients received midazolam as second-line AED. Of these, 22 (62.9\%) also received lidocaine, levetiracetam, and/or clonazepam as additional AED. Midazolam was considered effective in the remaining 13 (37.1\%) neonates. AED effectiveness is summarised in Table 3.

\section{Dosing Guideline Development}

Simulation datasets were created by replicating the patient characteristics of each neonate in the original dataset nine times, yielding simulation datasets of 1,017 patients for phenobarbital and 1,062 patients for midazolam. These datasets were used with the final PK parameter estimates to predict plasma concentrations after various dosing regimens.

Figure 3 shows predicted phenobarbital concentration-time curves after doses of 20,30 , and $40 \mathrm{mg} / \mathrm{kg}$ at PNA $4 \mathrm{~h}$. With $20 \mathrm{mg} / \mathrm{kg}, 46.7 \%$ of patients are within the proposed therapeutic range $(20-40 \mathrm{mg} / \mathrm{kg})$ directly after bolus infusion, dropping to $18.7 \%$ at PNA $48 \mathrm{~h} .30 \mathrm{mg} / \mathrm{kg}$ results in $90.2 \%$ within the therapeutic range directly after infusion and $85.4 \%$ at PNA $48 \mathrm{~h}$. A dose of $40 \mathrm{mg} / \mathrm{kg}$ leads to $53.2 \%$ within the therapeutic range directly after infusion and $80.7 \%$ at PNA $48 \mathrm{~h}$.

Figure 4 shows predicted concentration-time curves of midazolam with and without phenobarbital co-administration after a loading dose of $0.1 \mathrm{mg} / \mathrm{kg}$ followed by continuous infusion of $0.15 \mathrm{mg} / \mathrm{kg} / \mathrm{h}$. 
Table 2. Final model pharmacokinetic parameter estimates and SIR results

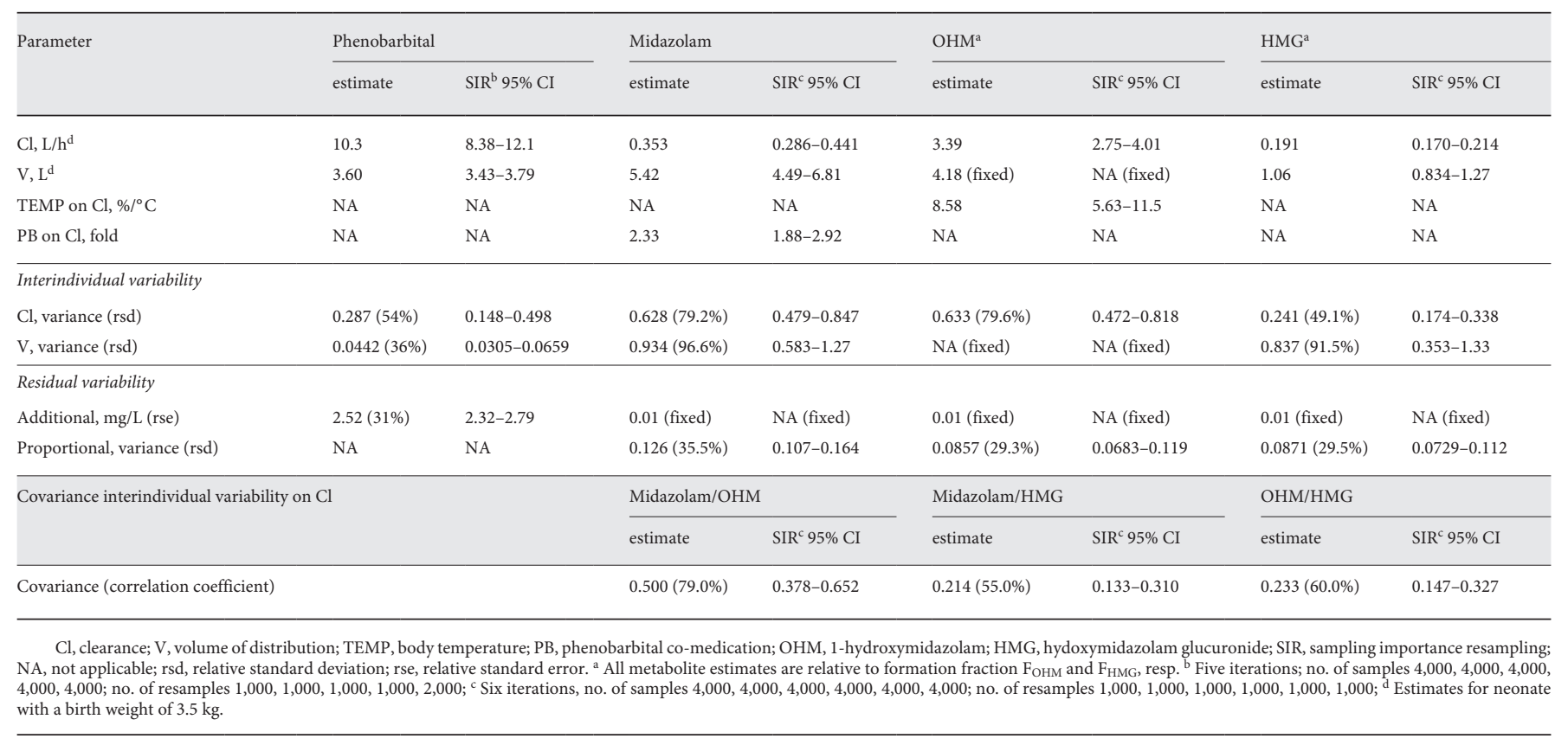

Table 3. Effectiveness of phenobarbital and midazolam as antiepileptic drugs

\begin{tabular}{lll}
\hline & Effective & Ineffective \\
\hline Phenobarbital $(n=113)$ & $74(65.5)$ & $39^{\mathrm{a}}(34.5)$ \\
Midazolam $(n=35)$ & $13(37.1)$ & $22(62.9)$ \\
\hline
\end{tabular}

Data are presented as $n(\%) .{ }^{\text {a }}$ Four patients unresponsive to phenobarbital received lidocaine instead of midazolam as secondline anti-epileptic drug.

\section{Discussion}

Data from this study confirm the previous findings that TH does not influence phenobarbital or midazolam clearance in neonates suffering from HIE. Clearance of OHM is reduced during $\mathrm{TH}$ compared to normothermia; clinicians should be aware that prolonged sedation could occur after cessation of midazolam during TH. Phenobarbital co-medication was found to significantly increase midazolam clearance. Although this effect has not been described previously, it has most likely been present in clinical practice for decades as both midazolam and phenobarbital are commonly used in neonates, often concomitantly for the treatment of seizures. Midazolam is usually titrated to the de- sired effect and/or tolerability of side effects independent of concomitant treatment with phenobarbital. Although adequate sedation and seizure control are crucial in neonates undergoing TH for HIE, concerns have been raised about both phenobarbital and midazolam use. Phenobarbital has been associated with neuronal toxicity in neonatal animal models and long-term cognitive and motor impairment in humans. Therefore, alternative first-line AEDs such as levetiracetam are currently being investigated [24]. As levetiracetam does not induce CYP3A, no influence on midazolam clearance is expected. In this situation, a reduction in midazolam maintenance dose by $50 \%$ is necessary to achieve similar plasma concentrations. Overexposure of midazolam should be avoided to minimise the risk of side effects such as hypotension and subsequent cerebral hypoperfusion when cerebral autoregulation is lost, and prolonged NICU admission $[6,8,25,26]$.

CYP3A is the most abundant subfamily of cytochrome P450 isozymes in the human liver and consists of at least three isoforms: CYP3A4, CYP3A5, and CYP3A7 [27]. CYP3A4 activity is relatively low at birth but increases over the first few weeks of life and reaches adult capacity between 6-12 months after birth. In adult livers, it accounts for $30-40 \%$ of all CYP content $[27,28]$. CYP3A5 is present at a much lower level compared to CYP3A4 and shows large interindividual variability. No maturational pattern of CYP3A5 has been identified [28]. CYP3A7 is 

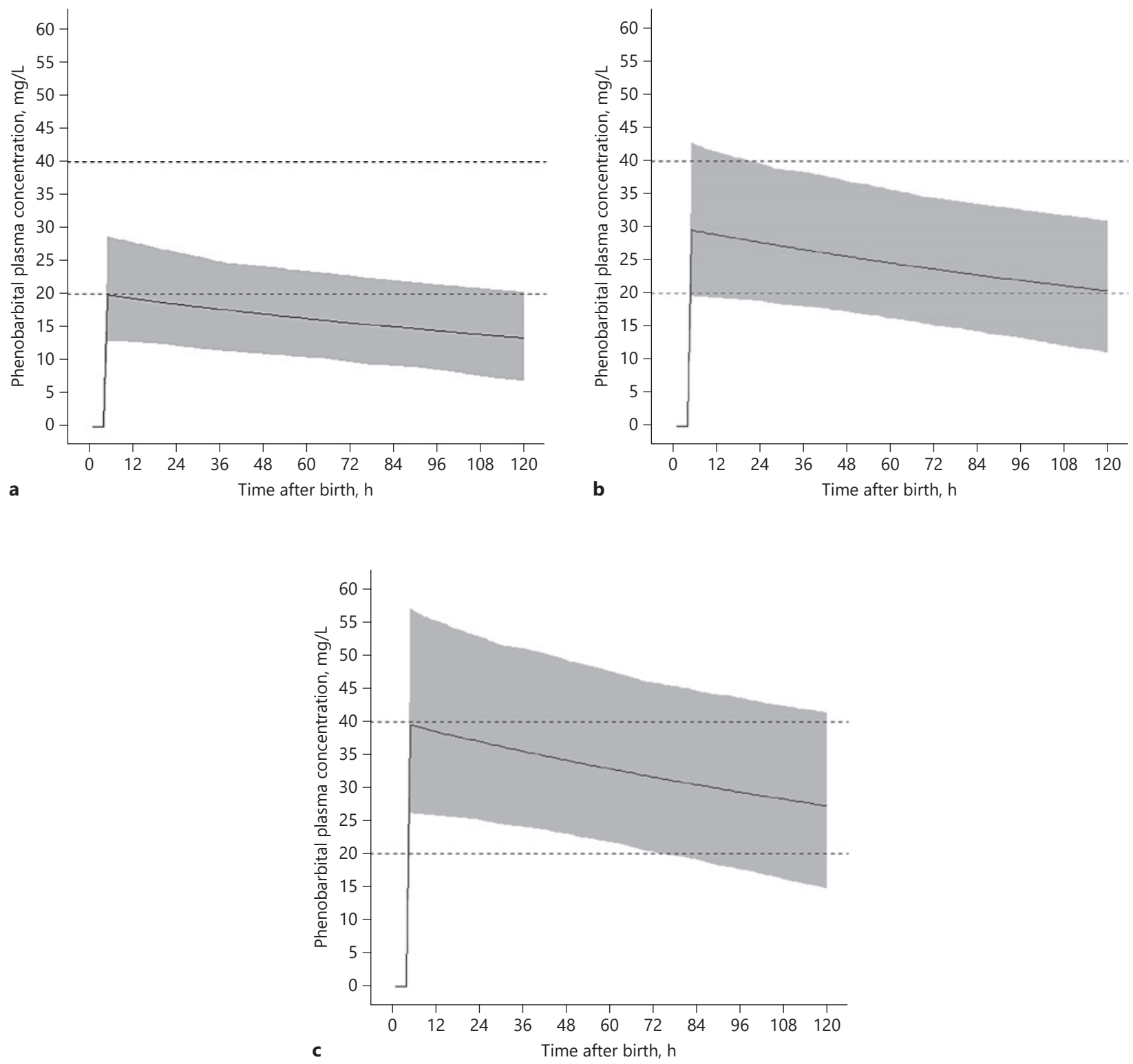

Fig. 3. Simulated phenobarbital plasma concentrations after a dose of $20 \mathrm{mg} / \mathrm{kg}$ (a), $30 \mathrm{mg} / \mathrm{kg}$ (b), and $40 \mathrm{mg} / \mathrm{kg}$ (c). Solid lines indicate the mean phenobarbital plasma concentrations. Dotted lines indicate the proposed therapeutic window; grey area represents the $95 \%$ prediction interval.

the major CYP isoform detected in the embryonic, foetal, and newborn liver but decreases thereafter. Compounds metabolised by CYP3A4 in adults are most likely primarily metabolised by CYP3A7 in neonates and infants up to 3 months of age [28, 29].

Induction of CYP enzymes is caused by an increase in gene transcription followed by upregulation of enzyme production. Unlike CYP inhibition, which is an almost immediate response, it is believed that CYP induction is a slower regulatory process which accumulates over time [30]. In adults, clinically relevant CYP3A induction has been described within $24 \mathrm{~h}$ after administration [31]. In asphyxiated neonates, both phenobarbital and midazolam are often administered within the first few hours after birth. In this study, blood sampling commenced on the second day after birth. As a time-dependent effect of 


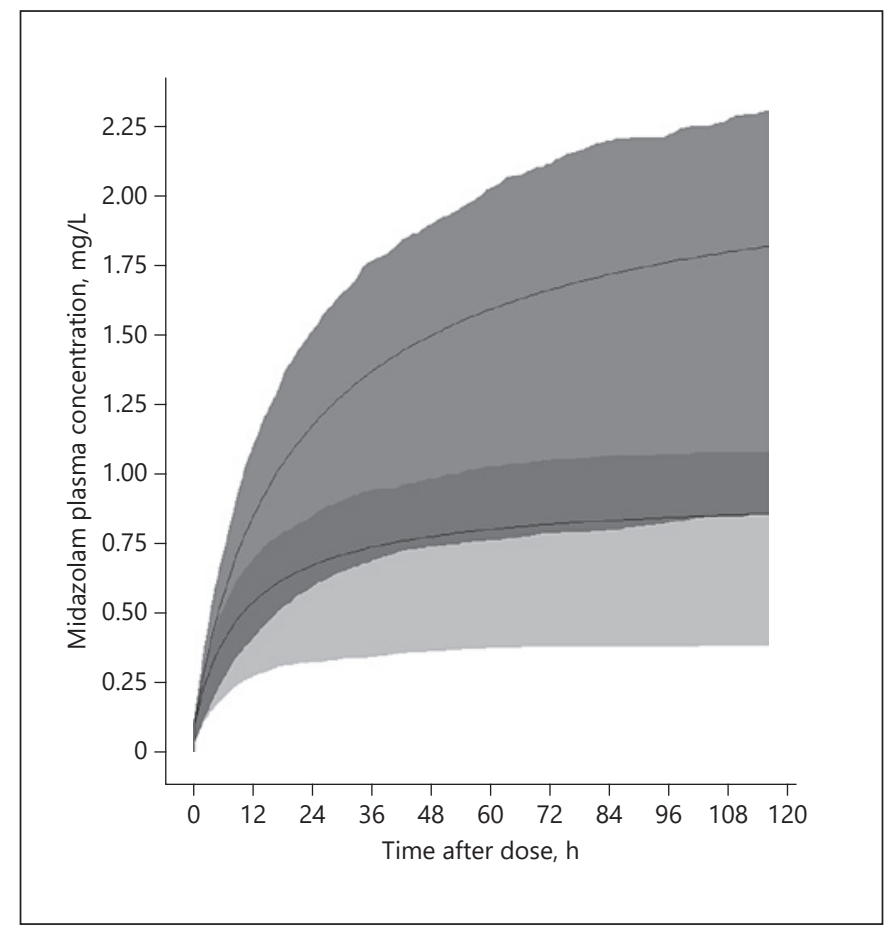

Fig. 4. Simulated midazolam plasma concentrations after a loading dose of $0.1 \mathrm{mg} / \mathrm{kg}$ followed by continuous infusion of $0.15 \mathrm{mg} / \mathrm{kg} / \mathrm{h}$. Upper solid line indicates the mean midazolam plasma concentration without phenobarbital co-medication. Bottom solid line indicates the mean midazolam plasma concentration with phenobarbital co-medication; grey areas represent the interquartile ranges.

phenobarbital on midazolam clearance was not identified, we hypothesise that the increasing effect of phenobarbital on CYP3A production in this population is clinically relevant as early as $24 \mathrm{~h}$ after birth.

In the past, phenobarbital has been used to treat hyperbilirubinaemia in predominantly preterm infants by inducing glucuronidation of unconjugated bilirubin [32]. Although OHM is glucuronated into HMG, no effect of phenobarbital co-medication on OHM clearance was identified. It is possible that glucuronidation is more developed in term neonates and that induction of glucuronidation is only relevant in preterm neonates as phenobarbital was unsuccessful in preventing hyperbilirubinaemia in term neonates [33]. Also, to our knowledge no drugdrug interactions between phenobarbital and drugs undergoing glucuronidation have been described in humans.

Table 1 clearly shows a difference in baseline characteristics between midazolam patients with and without phenobarbital co-administration. Neonates with phenobarbital co-medication had a more suppressed aEEG on admission and higher mortality, suggesting a more severe disease state.
However, increased midazolam clearance in this group by induction of CYP3A indicates that hepatic metabolic capacity is unaffected even in the most severe HIE cases.

Based on simulations performed in this study, a phenobarbital loading dose of $30 \mathrm{mg} / \mathrm{kg}$ is recommended to achieve plasma concentrations within the therapeutic window. An additional dose of $10 \mathrm{mg} / \mathrm{kg}$ can be given if seizures persist. This advice is in line with a recent study investigating phenobarbital PK in non-asphyxiated term and preterm neonates [34]. Phenobarbital effectiveness is comparable to previous reports $[4,5]$.

No changes to the midazolam dosing regimens are required in the current clinical practice. However, should phenobarbital be replaced as first-line AED, midazolam for additional seizure control should be titrated more carefully. Although responsiveness to midazolam in this study was higher than previously reported, its effectiveness as second-line AED remains limited $[4,8]$.

The data for this study were collected in neonates with a GA of $\geq 36$ weeks treated with TH for HIE. However, we believe that the interaction between phenobarbital and midazolam can be extrapolated to (near-)term neonates in general. As liver function might be hampered by TH and/ or HIE, the magnitude of the effect in non-asphyxiated normothermic neonates could be even greater. Extrapolation to preterm neonates should be done with caution due to possible maturational differences in CYP enzymes [13].

\section{Conclusion}

PK of phenobarbital and midazolam is unaffected by TH in (near-)term neonates treated with TH for HIE, and clinical effectiveness is comparable to previous reports. Phenobarbital significantly increased midazolam clearance. Should phenobarbital be substituted by non-CYPinducing drugs as first-line anticonvulsant, a lower midazolam dose is necessary to avoid excessive exposure across the entire neonatal population.

\section{Acknowledgements}

The following PharmaCool study group members are non-author contributors: Mieke J. Brouwer, $\mathrm{PhD}^{\mathrm{b}}$; S.M. Mulder-de Tollenaer, $\mathrm{MD}, \mathrm{PhD}^{\mathrm{f}}$; L.J.M. Groot Jebbink-Akkerman, $\mathrm{MD}, \mathrm{PhD}^{\mathrm{f}}$; Diien Liem, $\mathrm{MD}, \mathrm{PhD}^{\mathrm{h}}$; Katerina Steiner, $\mathrm{MD}, \mathrm{PhD}^{\text {h }}$; Jeroen Dudink, $\mathrm{MD}, \mathrm{PhD}^{\mathrm{i}}$; Rogier C.J. de Jonge $\mathrm{MD}, \mathrm{PhD}^{\mathrm{i}}$; Annelies $\mathrm{A}$. Bos, MD, $\mathrm{PhD}^{\mathrm{i}}$; Michel Sonnaert, $\mathrm{MD}, \mathrm{PhD}^{\mathrm{m}}$; Fleur Anne Camfferman, $\mathrm{MD}, \mathrm{PhD}^{\mathrm{m}}$. Affiliations correspond with author affiliations.

The authors would like to thank Mark de Groot for contributions with regard to data management. 


\section{References}

1 Jacobs SE, Berg M, Hunt R, Tarnow-Mordi WO, Inder TE, Davis PG. Cooling for newborns with hypoxic ischaemic encephalopathy. Cochrane Database Syst Rev. 2013 Jan;(1):CD003311.

2 Azzopardi DV, Strohm B, Edwards AD, Dyet L, Halliday HL, Juszczak E, et al.; TOBY Study Group. Moderate hypothermia to treat perinatal asphyxial encephalopathy. $\mathrm{N}$ Engl J Med. 2009 Oct;361(14):1349-58

3 Groenendaal F, Casaer A, Dijkman KP, Gavilanes AW, de Haan TR, ter Horst HJ, et al. Introduction of hypothermia for neonates with perinatal asphyxia in the Netherlands and Flanders. Neonatology. 2013;104(1):1521.

4 El-Dib M, Soul JS. The use of phenobarbital and other anti-seizure drugs in newborns. Semin Fetal Neonatal Med. 2017 Oct;22(5):3217.

5 van den Broek MP, Groenendaal F, Toet MC, van Straaten HL, van Hasselt JG, Huitema $\mathrm{AD}$, et al. Pharmacokinetics and clinical efficacy of phenobarbital in asphyxiated newborns treated with hypothermia: a thermopharmacological approach. Clin Pharmacokinet. 2012 Oct;51(10):671-9.

6 Weeke LC, Toet MC, Van Rooij LGM, Groenendaal F, Boylan GB, Pressler RM, et al. Lidocaine response rate in aEEG-confirmed neonatal seizures: Retrospective study of 413 full-term and preterm infants. Epilepsia. 2016 Feb;57(2):233-42.

7 Carbajal R, Eriksson M, Courtois E, Boyle E, Avila-Alvarez A, Andersen RD, et al.; EUROPAIN Survey Working Group. Sedation and analgesia practices in neonatal intensive care units (EUROPAIN): results from a prospective cohort study. Lancet Respir Med. 2015 Oct;3(10):796-812.

8 van den Broek MP, van Straaten HL, Huitema AD, Egberts T, Toet MC, de Vries LS, et al. Anticonvulsant effectiveness and hemodynamic safety of midazolam in full-term infants treated with hypothermia. Neonatology. 2015;107(2):150-6

9 Young CC, Prielipp RC. Benzodiazepines in the intensive care unit. Crit Care Clin. 2001 Oct;17(4):843-62.

10 Van Leuven K, Groenendaal F, Toet MC, Schobben AF, Bos SA, De Vries LS, et al. Midazolam and amplitude-integrated EEG in asphyxiated full-term neonates. Acta Paediatr. 2004 Sep;93(9):1221-7.

11 Bauer TM, Ritz R, Haberthür C, Ha HR, Hunkeler W, Sleight AJ, et al. Prolonged sedation due to accumulation of conjugated metabolites of midazolam. Lancet. $1995 \mathrm{Jul}$; 346(8968):145-7.
12 Chu V, Einolf HJ, Evers R, Kumar G, Moore $\mathrm{D}$, Ripp S, et al. In vitro and in vivo induction of cytochrome p450: a survey of the current practices and recommendations: a pharmaceutical research and manufacturers of america perspective. Drug Metab Dispos. 2009 Jul; 37(7):1339-54.

13 Kearns GL, Abdel-Rahman SM, Alander SW, Blowey DL, Leeder JS, Kauffman RE. Developmental pharmacology-drug disposition, action, and therapy in infants and children. N Engl J Med. 2003 Sep;349(12): 1157-67.

14 van den Anker J, Reed MD, Allegaert K, Kearns GL. Developmental Changes in Pharmacokinetics and Pharmacodynamics. J Clin Pharmacol. 2018 Oct;58 Suppl 10:S10-25.

15 Glass HC, Nash KB, Bonifacio SL, Barkovich AJ, Ferriero DM, Sullivan JE, et al. Seizures and magnetic resonance imaging-detected brain injury in newborns cooled for hypoxicischemic encephalopathy. J Pediatr. 2011 Nov;159(5):731-735.e1.

16 McBride MC, Laroia N, Guillet R. Electrographic seizures in neonates correlate with poor neurodevelopmental outcome. Neurology. 2000 Aug;55(4):506-13.

17 Campbell C, Wells G, Jacob P. Seizure-associated brain injury in term newborns with perinatal asphyxia. Neurology. 2002 Oct;59(7): 1119; author reply 1119-20.

18 van den Broek MP, Groenendaal F, Egberts AC, Rademaker CM. Effects of hypothermia on pharmacokinetics and pharmacodynamics: a systematic review of preclinical and clinical studies. Clin Pharmacokinet. 2010 May; 49(5):277-94.

19 Tortorici MA, Kochanek PM, Poloyac SM. Effects of hypothermia on drug disposition, metabolism, and response: A focus of hypothermia-mediated alterations on the cytochrome P450 enzyme system. Crit Care Med. 2007 Sep;35(9):2196-204.

20 Zanelli S, Buck M, Fairchild K. Physiologic and pharmacologic considerations for hypothermia therapy in neonates. J Perinatol. 2011 Jun;31(6):377-86.

21 de Haan TR, Bijleveld YA, van der Lee JH, Groenendaal F, van den Broek MP, Rademaker CM, et al. Pharmacokinetics and pharmacodynamics of medication in asphyxiated newborns during controlled hypothermia. The PharmaCool multicenter study. BMC Pediatr. 2012 May; 12(1):45.

22 Keizer RJ, Karlsson MO, Hooker A. Modeling and Simulation Workbench for NONMEM: Tutorial on Pirana, PsN, and Xpose. CPT Pharmacometrics Syst Pharmacol. 2013 Jun; 2(6):e50.
23 Dosne AG, Bergstrand M, Harling K, Karlsson MO. Improving the estimation of parameter uncertainty distributions in nonlinear mixed effects models using sampling importance resampling. J Pharmacokinet Pharmacodyn. 2016 Dec;43(6):583-96.

24 McHugh D, Lancaster S, Manganas L: A Systematic Review of the Efficacy of Levetiracetam in Neonatal Seizures. Neuropediatrics 2018;49:012-017.

$25 \mathrm{Ng} \mathrm{E}$, Taddio A, Ohlsson A. Intravenous midazolam infusion for sedation of infants in the neonatal intensive care unit. Cochrane Database Syst Rev. 2017 Jan;1:CD002052.

26 Thoresen M, Satas S, Løberg EM, Whitelaw A, Acolet D, Lindgren C, et al. Twenty-four hours of mild hypothermia in unsedated newborn pigs starting after a severe global hypoxic-ischemic insult is not neuroprotective. Pediatr Res. 2001 Sep;50(3):405-11.

27 de Wildt SN, Kearns GL, Leeder JS, van den Anker JN. Cytochrome P450 3A: ontogeny and drug disposition. Clin Pharmacokinet. 1999 Dec;37(6):485-505.

28 Hines RN. Ontogeny of human hepatic cytochromes P450. J Biochem Mol Toxicol. 2007; 21(4):169-75.

29 Strougo A, Yassen A, Monnereau C, Danhof M, Freijer J. Predicting the "First dose in children” of CYP3A-metabolized drugs: evaluation of scaling approaches and insights into the CYP3A7-CYP3A4 switch at young ages. J Clin Pharmacol. 2014 Sep;54(9):1006-15.

$30 \mathrm{Lin} \mathrm{JH}, \mathrm{Lu} \mathrm{AY}$. Inhibition and induction of cytochrome P450 and the clinical implications. Clin Pharmacokinet. 1998 Nov;35(5): 361-90.

31 Huitema AD, Mathôt RA, Tibben MM, Rodenhuis S, Beijnen JH. A mechanism-based pharmacokinetic model for the cytochrome P450 drug-drug interaction between cyclophosphamide and thioTEPA and the autoinduction of cyclophosphamide. J Pharmacokinet Pharmacodyn. 2001 Jun;28(3):211-30.

32 Chawla D, Parmar V. Phenobarbitone for prevention and treatment of unconjugated hyperbilirubinemia in preterm neonates: a systematic review and meta-analysis. Indian Pediatr. 2010 May;47(5):401-7.

33 Arya V, Agarwal R, Paul V, Deorari A. Efficacy of Oral Phenobarbitone in Term "at risk" Neonates in Decreasing Neonatal Hyperbilirubinaemia:aRandomizedDouble-Blinded,Placebo Controlled Trial. Indian J Pediatr. 2004.

34 Völler S, Flint RB, Stolk LM, Degraeuwe PL, Simons SH, Pokorna P, et al.; DINO study group. Model-based clinical dose optimization for phenobarbital in neonates: an illustration of the importance of data sharing and external validation. Eur J Pharm Sci. 2017 Nov;109S:S90-7. 